\title{
Obesity and COVID-19: A Perspective from the European Association for the Study of Obesity on Immunological Perturbations, Therapeutic Challenges, and Opportunities in Obesity
}

\author{
Gijs H. Goossens ${ }^{a}$, b Dror Dicker ${ }^{a, c}$ Nathalie J. Farpour-Lambert ${ }^{a}$ d \\ Gema Frühbeck $^{a, e}$ Dana Mullerova ${ }^{a}$ f Euan Woodward ${ }^{a, g}$ \\ Jens-Christian Holma, $\mathrm{h}$ \\ aEuropean Association for the Study of Obesity, Teddington, UK; ${ }^{b}$ Department of Human \\ Biology, NUTRIM School of Nutrition and Translational Research in Metabolism, Maastricht \\ University Medical Centre, Maastricht, The Netherlands; ${ }^{C}$ Department of Internal Medicine \\ D and Obesity Clinic, Hasharon Hospital, Rabin Medical Center, Petah Tikva, Sackler School \\ of Medicine, Tel Aviv University, Tel Aviv, Israel; d Obesity Prevention and Care Program \\ Contrepoids, Service of Endocrinology, Diabetology, Nutrition, and Therapeutic Patient \\ Education, Department of Medicine, Geneva University Hospitals and University of Geneva,

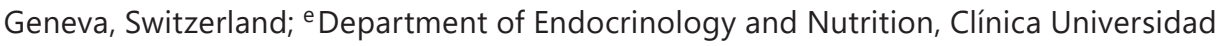 \\ de Navarra, University of Navarra, IdiSNA, CIBEROBN, Spanish Health Institute Carlos \\ III, Pamplona, Spain; ; Department of Public Health and Preventive Medicine, Faculty of \\ Medicine in Pilsen, Charles University, Pilsen, Czechia; ${ }^{9}$ European Association for the Study

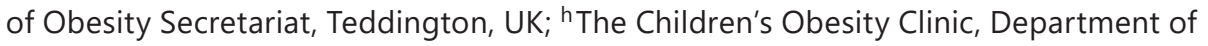 \\ Pediatrics, Holbæk University Hospital, Holbæk, Denmark
}

\section{Keywords}

Severe acute respiratory syndrome coronavirus $2 \cdot$ SARS-CoV-2 - ACE2 - Coronavirus disease $2019 \cdot$ COVID-19 · Obesity · Renin-angiotensin-aldosterone system · Immune response

\begin{abstract}
Accumulating evidence suggests that obesity is a major risk factor for the initiation, progression, and outcomes of coronavirus disease 2019 (COVID-19). The European Association for the Study of Obesity (EASO), as a scientific and medical society dedicated to the promotion of health and well-being, is greatly concerned about the concomitant obesity and COVID-19 pandemics and their impact on health and society at large. In this perspective, we will address the inherent immunological perturbations and alterations in the renin-angiotensin-aldosterone system in patients with obesity and COVID-19, and discuss how these impairments may underlie the increased susceptibility and more detrimental outcomes of COVID-19 in people with obesity. Clearly, this has important implications for preventive measures, vaccination, and
\end{abstract}


future therapeutic strategies to combat COVID-19. Furthermore, we will highlight important knowledge gaps and provide suggestions for future research and recommendations for policy actions. Since many new reports on COVID-19 rapidly appear, the present perspective should be seen as a focus for discussion to drive forward further understanding, research initiatives, and clinical management of COVID-19.

\section{Introduction}

Coronavirus disease 2019 (COVID-19), the infectious disease caused by the novel coronavirus severe acute respiratory syndrome coronavirus 2 (SARS-CoV-2), was declared a pandemic by the World Health Organization on March 11, 2020 [1] and continues to spread across the globe. Although hospital admission rates for patients with COVID-19 depend on community testing and admission criteria, it has been estimated that one in 5-10 adults has illnesses requiring hospital admission [2], with rates of admission to the intensive care unit (ICU) in China, Europe, and the United States ranging from 5 to 32\% [3-11].

The European Association for the Study of Obesity (EASO), as a scientific and medical society dedicated to the promotion of health and well-being, is greatly concerned about the collision of the obesity and COVID-19 pandemics and its impact on individuals, families, communities, health systems, and society at large [12]. Early identification of individuals who are especially susceptible to developing severe COVID-19 and will be admitted to the ICU is crucial.

Obesity is a gateway to many noncommunicable diseases (NCDs) $[13,14]$, and people with obesity in general seem to have an elevated risk of hospitalization, serious illness, and mortality. With the rising prevalence of obesity has come an increasing awareness of its impact on communicable disease. Indeed, as a consequence of the $2009 \mathrm{H} 1 \mathrm{~N} 1$ influenza A virus pandemic, obesity was identified for the first time as an independent risk factor for increased disease severity and mortality in infected individuals $[15,16]$. A recent meta-analysis, which was published in early April 2020, provided evidence that obesity-related complications are major risk factors associated with COVID-19 [17]. Furthermore, people with obesity were more likely to require acute care and admission to the ICU, intubation, and mechanical ventilation [18-23], especially among those younger than 60 years [20]. A recent report from France has provided additional evidence for the strong association between obesity and severe complications from COVID-19 [24]. Moreover, it has consistently been demonstrated that old age, male sex, and chronic major comorbidity, including obesity, are associated with increased mortality in patients with COVID-19 [5-8]. Since obesity and obesity-associated comorbidities often cluster together, the independent contribution of each factor to the development and progression of COVID-19 has not been determined in many studies. Interestingly, however, a large prospective observational cohort study, in which more than 20,000 hospital inpatients with COVID-19 in the United Kingdom during the growth phase of the first wave of this outbreak were enrolled, has very recently demonstrated that obesity was an independent risk factors for high mortality [11]. Together, these findings highlight the detrimental outcomes of COVID-19 in people with obesity and underscore the importance of continuous obesity management and care during the COVID-19 pandemic.

In this perspective, we will address the inherent immunological perturbations and increased activity of the renin-angiotensin-aldosterone system (RAAS) in obesity and how this may increase COVID-19 susceptibility in people living with obesity. Furthermore, we will discuss therapeutic challenges, highlight knowledge gaps, and provide suggestions for future (research) strategies. 


\section{Obesity and COVID-19: Shared Immunological Perturbations}

Evidence from studies in humans indicates that people with obesity are characterized by systemic low-grade inflammation, higher susceptibility to infections, dampened immune response to infectious agents, as well as higher morbidity and mortality associated with infections, and demonstrate an impaired immune response to vaccinations and antimicrobial treatment [25-28]. In this section, we will discuss the link between obesity, immunological perturbations, increased activity of the RAAS, and elevated susceptibility to and severity of COVID-19. Clearly, this has important implications for prevention and treatment strategies during the current collision of the obesity and COVID-19 pandemics.

\section{Immunological Alterations in Obesity}

Compelling evidence suggests that the excess adipose tissue mass in people with obesity directly contributes to the immunological perturbations in obesity. Adipose tissue is a highly dynamic, metabolically active organ that plays a central role in many physiological processes, including immunity and inflammation $[29,30]$. In healthy conditions, adipose tissue produces and releases a multitude of factors, including pro- and anti-inflammatory factors, to maintain tissue homeostasis [31]. It is well established that the enlarged fat cells (hypertrophic adipocytes) in the expanded fat mass in people with obesity are characterized by a proinflammatory phenotype, which is closely associated with obesity-related complications and NCDs such as type 2 diabetes, cardiovascular diseases, and several types of cancer [29, 30]. In addition to detrimental autocrine and paracrine effects of a proinflammatory adipose tissue microenvironment in obesity, increased secretion of multiple proinflammatory cytokines (for example, interleukin-6 [IL-6] [32,33]) together with reduced secretion of adiponectin by obese adipose tissue seem to contribute to sustained low-grade systemic inflammation in obesity and obesity-related NCDs in humans [29, 30, 34, 35].

Importantly, adipose tissue inflammation is not only caused by secretion of proinflammatory factors from adipocytes, but also by infiltration of various populations of specialized, proinflammatory immune cells [30,35]. Macrophages exert a key role as part of the innate immune system by phagocytosis of harmful pathogens and apoptotic or necrotic cells. In obesity, the population of proinflammatory macrophages within adipose tissue is increased, and these cells become metabolically activated, secrete proinflammatory cytokines, and engage in inflammatory crosstalk with other immune cells [30,36], thereby contributing to a proinflammatory phenotype of adipose tissue as well as systemic low-grade inflammation.

Innate immunity is the first line of defense against virus invasion. Once primed by the earlier innate response, lymphocytes of the adaptive immune system continue the control and removal of pathogens. Viral infection of mammals activates intracellular pattern recognition receptors that sense pathogen-associated molecular patterns. The recognition of pathogen-associated molecular patterns results in subsequent cytolytic immune responses, mainly through type I interferons and natural killer cells. Adaptive immunity also contributes to viral clearance via activated cytotoxic $\mathrm{T}$ cells that destroy virus-infected cells, and via antibody-producing B cells that target virus-specific antigens [37]. Thus, T cells exert a prominent role in the response to infection by supporting the function and activation of other immune cells such as macrophages, as well as by regulating the activity of different $\mathrm{T}$ cell subsets, to produce pro- and anti-inflammatory factors [35]. Together, these distinct populations of immunologically adaptive immune cells play a critical role in combating pathogens.

While the majority of studies investigating the relationship between obesity and inflammation have focused on the role of macrophages, more recent studies clearly point to an important role for the adaptive immune system. Several studies have implicated proinflammatory $\mathrm{T}$ and $\mathrm{B}$ cell phenotypes in obesity-related adipose tissue inflammation [38]. Impor- 
tantly, obesity dampens and delays the adaptive immune response to infection, with reduced efficacy of both $\mathrm{T}$ and $\mathrm{B}$ cell responses in obesity, as extensively reviewed elsewhere $[25,35$, 36]. Many factors that could potentially impact the immune response are impaired in obesity, including increased leptin concentrations, altered immune cell metabolism, and epigenetic factors, and may therefore underlie the impaired immune response to infectious disease in obesity [39]. Intriguingly, a growing body of evidence supports the notion that impaired immunological responses to infection in people living with obesity are driven by perturbations in T cell activation and function [35]. Interestingly, recent studies have demonstrated that the innate immune system, like the adaptive immune system, is able to adopt a long-term activated phenotype by previous encounters with microbial stimuli, leading to an increased immune response upon secondary stimulation ("trained innate immunity") [34]. Although the association between obesity and trained immunity remains elusive, several known inducers of trained immunity such as cytokines and (saturated) fatty acids are elevated in people with obesity [34].

Inherent immunological deficits in obesity may contribute to more detrimental outcomes in people with obesity when encountering COVID-19. As mentioned earlier, people with obesity exhibit an impaired immune response to infectious agents, increased viral load and life cycle, and experience poorer outcomes and recovery from infections [25-27]. In line with an impaired immunological response to infection, reduced effectiveness of antivirals and vaccination has been found in people with obesity $[25,26]$, leaving them more vulnerable to infection. Indeed, a lower CD8+ T cell response and a more pronounced decline in influenza antibody titers 1 year after vaccination have been reported in people with obesity compared to individuals with normal weight [40]. The latter finding is indicative of an inadequate immune response to influenza virus in obesity, which is likely explained by defects in activation and function of CD4+ and CD8+ T cells [41]. Taken together, perturbations in both the innate and adaptive arms of the immune system are present in people with obesity, and this likely has important implications for the prevention and treatment of COVID-19-associated complications, as will be discussed later.

\section{Immunological Alterations in COVID-19}

The invasion and pathogenesis of SARS-CoV-2 are associated with the host immune response. The antiviral immune response is crucial to eliminate the invading virus, but a robust and persistent antiviral immune response might also cause massive production of inflammatory cytokines and damage to host tissues [42]. The overproduction of cytokines caused by aberrant immune activation is known as a cytokine storm. In fact, in the late stages of coronavirus disease, including SARS, Middle East respiratory syndrome, and COVID-19, cytokine storms are a major cause of disease progression and eventual death [43-45].

In COVID-19 patients, elevated plasma concentrations of both proinflammatory Th1 and anti-inflammatory Th2 cytokines were found [3]. Notably, patients admitted to the ICU had higher plasma concentrations of IL-2, IL-7, IL-10, granulocyte colony-stimulating factor, interferon gamma-induced protein 10 , macrophage chemoattractant protein 1 , macrophage inflammatory protein $1 \alpha$, and tumor necrosis factor alpha compared to those not admitted to the ICU [3]. IL-6 is a key inflammatory cytokine that plays a critical part in the inflammatory cytokine storm, and it has been found that plasma IL- 6 concentrations were above the normal range in patients with severe symptoms of COVID-19 compared with healthy individuals and those with milder symptoms [46-48]. IL-6-producing CD14+ CD16+ inflammatory monocytes were significantly increased in patients with COVID-19, and this subset of immune cells was further increased in patients admitted to the ICU [49]. In agreement with these findings, in particular COVID-19 patients with severe pneumonia seem to have substantially lower lymphocyte counts and higher plasma concentrations of a number of inflammatory cytokines,

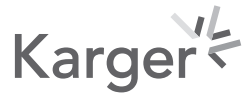


including IL-6 and tumor necrosis factor alpha $[3,48,50]$, providing further evidence that cytokine storms may play a crucial role in COVID-19 severity. SARS-CoV-2 infection may affect primarily $\mathrm{T}$ lymphocytes, particularly CD4+ and CD8+ $\mathrm{T}$ cells. Indeed, it has been reported that CD4+ T cells, CD8+ T cells, and natural killer cells [48], as well as the expression of interferon gamma by CD4+ T cells [47], were reduced in severely ill patients compared with those with mild disease symptoms.

Since cytokine storms determine disease progression and mortality [43-45], early identification and appropriate treatment of this hyperinflammatory status are important in patients with COVID-19 [51]. It has been proposed that a combination of clinical and laboratory tests of ferritin, lymphocyte or leukocyte counts, platelet counts, erythrocyte counts, and sedimentation rate could be used to identify patients with COVID-19 at high risk of hyperinflammation [51]. Interestingly, results from a recent retrospective study, stratifying patients with COVID-19 by survival or disease severity, have suggested that percentage of circulating lymphocytes, levels of C-reactive protein, IL-6, procalcitonin, and viral load (ORF1ab Ct) could predict prognosis (survival/nonsurvival) and guide classification (moderate/severe/critically ill) of COVID-19 patients, with percentage of circulating lymphocytes being the most sensitive and reliable predictor for disease typing and prognosis [52]. Of note, it has recently been reported in the UK Biobank community cohort that the $A p o E$ e $4 \mathrm{e} 4$ allele predicts severe COVID-19, independent of preexisting dementia, cardiovascular disease, and type 2 diabetes [53]. Since apolipoprotein E exerts atheroprotective and anti-inflammatory effects (including modulation of macrophage phenotype and CD4+ and CD8+ lymphocytes) and has previously been implicated in viral infections [54], apolipoprotein E genotype might be considered in prediction models for COVID-19 severity. Together, these findings imply that evaluation of cytokine profiles and immune cell subsets in patients with SARS-CoV-2 infection, and a deeper understanding of the underlying processes, will significantly contribute to better treatment strategies and clinical management of COVID-19 [37].

To summarize, there are clear parallels between obesity and COVID-19 in terms of immunological perturbations. As outlined above, available evidence suggests that obesity is a major risk factor for the initiation and progression of COVID-19. Based on the available evidence, it is tempting to postulate that increased activity of the RAAS explains why COVID-19 is more prevalent and is related to more detrimental outcomes in people living with obesity, as will be discussed below.

ACE2: Linking the Renin-Angiotensin System, Obesity-Related Complications, and COVID-19

The RAAS comprises several vasoactive peptides involved in many key physiological processes in humans. The RAAS has long been recognized as an important regulator of renal electrolyte homeostasis and blood pressure [55-57]. The dipeptidyl carboxypeptidase angiotensin-converting enzyme (ACE) rapidly converts angiotensin I (Ang I) to Ang II, which is the major effector peptide of the RAAS [55-57]. Different RAAS components are present in a variety of tissues such as the adrenal gland, kidney, liver, heart, blood vessels, brain, lung, and adipose tissue, implying that these tissues have the ability to locally synthesize Ang II [55]. Importantly, Ang II mediates proinflammatory signaling, thrombotic processes, cell growth, reactive oxygen species generation, and fibrosis and contributes to pathological changes of organ structure and function [55,57]. Multiple lines of evidence have established that increased RAAS activation is involved in the pathophysiology of obesity-related diseases, including type 2 diabetes [58] and cardiovascular diseases [59].

ACE2 is a monocarboxypeptidase that mitigates the deleterious actions of Ang II by converting it into the heptapeptide Ang-(1-7) $[60,61]$. ACE2 has been identified as the functional receptor for SARS-CoV-1 [62] as well as the SARS-CoV-2 receptor [63-65]. The spike glycoprotein on the viral envelope of SARS-CoV-2 binds to ACE2 on the surface of human cells

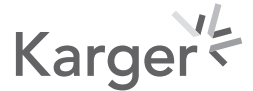


for intracellular invasion $[64,65]$. Following binding, ACE2 activity is downregulated through multiple mechanisms, which prevents it from converting Ang II into Ang-(1-7) [66]. The interaction between the SARS viruses and ACE2 has been proposed as a potential factor in their infectivity $[67,68]$. Like other RAAS components, ACE2 is expressed in many tissues, including the lungs, cardiovascular system, gut, kidneys, pancreas, testis, central nervous system, and adipose tissue [60]. It has been suggested that alveolar macrophages expressing ACE2 are the primary target cells for SARS-CoV- 2 infection, and these activated macrophages may play a major role in the cytokine storm during COVID-19 [69]. In agreement with this, immune-mediated lung injury and acute respiratory distress syndrome are associated with adverse outcomes in patients with COVID-19 [43]. Thus, ACE2 expression and/or activity in target tissues might facilitate entry of SARS-CoV-2 spike protein, induce the cytokine storm and, therefore, determine the severity of complications and prognosis in patients with COVID-19 [70]. In line with ACE2 downregulation following SARS-CoV-2 binding to ACE2, circulating Ang II concentrations were markedly elevated in a small cohort of 12 patients with COVID-19 compared to healthy controls and were linearly associated with viral load and lung injury [71]. This provides a direct link between tissue ACE2 downregulation, increased Ang II action, and the increased risk of multiorgan damage from SARS-CoV-2 infection.

Obesity is characterized by increased activation of the systemic and local adipose tissue RAAS [55, 57]. Since the expression of several RAAS components is increased in adipose tissue of people with obesity and Ang II has deleterious effects in multiple organs, it is tempting to postulate that ACE2 in adipose tissue may provide a critical link between obesity, NCDs, and the susceptibility to and severity of COVID-19. Moreover, since aging is accompanied by an increased abdominal fat mass, it may well be that the adipose tissue-SARS-CoV-2-RAAS axis at least partially contributes to the higher risk of COVID-19-associated complications and more detrimental outcomes in elderly. Clearly, further mechanistic studies in humans are needed to elucidate the interplay between the RAAS and SARS-CoV-2.

\section{Therapeutic Strategies to Combat COVID-19: Challenges and Opportunities}

Until now, there is no approved effective vaccine or drug for SARS-CoV-2 infection, and the most common treatment for patients with COVID-19 is supportive care. Certain compounds have been shown to inhibit SARS-CoV-2 infection in cell culture models [72, 73]. Interestingly, a SARS-CoV-2 hACE2 transgenic mouse infection model has recently been developed [74]. The infected mice generated typical interstitial pneumonia and pathology that were similar to those of COVID-19 patients. Strikingly, pre-exposure to SARS-CoV-2 could protect these mice from severe pneumonia [74]. Since there is currently no specific antiviral therapy against SARS-CoV-2, the hACE2 mouse may provide a valuable preclinical model to investigate potential vaccines and therapeutic agents before moving to clinical trials in humans.

In response to the COVID-19 pandemic, an overwhelming number of clinical trials have been registered to test a variety of preventive and therapeutic strategies [75]. Since COVID-19 rapidly evolved and requires immediate clinical treatment due to its relatively high mortality, extensive preclinical evidence concerning the feasibility, safety, and efficacy of pharmacological interventions is mostly lacking [75]. Thus, the scientific quality of many clinical COVID-19 studies is of serious concern. Although multiple antiviral drugs have been used in clinical practice $[5,76]$, their safety and efficacy remains to be established. Current COVID-19 studies are mainly based on repurposing existing pharmacological agents with proven effectiveness in other conditions that seem to share a comparable pathophysiology with COVID-19 [77]. This approach takes advantage of existing detailed information on human pharmacology and toxicology to enable rapid clinical trials and regulatory review. 


\section{Immune-Modulating Drugs}

Given the importance of immune imbalance in the pathogenesis of SARS-CoV-2 infection, several immune-modulating drugs that regulate different aspects of inflammation are currently being tested for their efficacy in the treatment of severe COVID-19 [37, 75]. Since hyperinflammation is an important determinant of tissue damage, organ failure, and disease outcome in COVID-19, immunosuppression might reduce mortality in patients with severe symptoms [43, 51]. Of note, antiviral immunity is required to recover from COVID-19, which implies that the use of (broad) immunosuppressants in patients with this disease should be carefully considered, taking the extent of (hyper)inflammation, viral load or replication status, disease stage, and pharmacokinetics of immunosuppressants into account, in particular in more vulnerable populations such as people with obesity.

Chloroquine and Hydroxychloroquine. Chloroquine and hydroxychloroquine, initially used as antimalarial drugs and widely used in several infectious, rheumatological, and other immunological diseases [78], are currently under investigation for the prevention and treatment of COVID-19 [37, 75]. These agents both increase the endosomal pH required for SARS-CoV-2 endocytosis and cell fusion, and chloroquine further interferes with glycosylation of the SARS-CoV-2 receptor, ACE2 [79]. In line with these findings, it has recently been shown that chloroquine is highly effective in the control of SARS-CoV-2 infection in vitro [72]. The use of antimalarial drugs such as (hydroxy)chloroquine was associated with lower infection risk compared to other immunosuppressants [80,81]. Although results of a small, uncontrolled trial suggested that hydroxychloroquine accelerated virus load reduction and disappearance in patients with COVID-19 [82], this study has been criticized [83]. Furthermore, a randomized clinical trial indicated that hydroxychloroquine treatment may have clinical benefits in patients with COVID-19 [84]. Importantly, however, no evidence of clinical efficacy has been reported [85-87], and a retrospective analysis of data from patients hospitalized with confirmed SARS-CoV-2 infection even demonstrated increased overall mortality in patients treated with hydroxychloroquine [88]. Moreover, since (high-dose) chloroquine may induce arrhythmias, caution is needed on the use of (hydroxy)chloroquine to treat COVID-19 [89].

Selective JAK1/JAK2 Blockade. Selective blockade of Janus kinase (JAK) by synthetic molecule compounds (i.e., targeted synthetic immunosuppressants) may reduce viral invasion and induce immune suppression. Indeed, it has been predicted that the selective JAK1 and JAK2 inhibitor baricitinib might reduce the ability of the SARS-CoV-2 virus to infect lung cells [90]. In addition, the immunosuppressive function of baricitinib might also be of benefit to the hyperactive immune status in severe cases of COVID-19 [37]. Another specific JAK1/JAK2 inhibitor, ruxolitinib, has been successfully used for the treatment of secondary hemophagocytic lymphohistiocytosis [37], a disease entity that like COVID-19 is also characterized by an uncontrolled cytokine storm [91]. Several clinical trials are underway to assess the efficacy of these selective JAK1/JAK2 blockers [37, 75].

Blockade of Cytokine Receptors. Blockade of proinflammatory cytokine receptors and its downstream signaling pathways using monoclonal antibodies (i.e., biological immune-modulating drugs) seems a potential intervention to combat the inflammatory cytokine storm in patients with COVID-19. Tocilizumab, a recombinant humanized monoclonal antibody against the IL- 6 receptor, binds both the membrane and soluble forms of the IL- 6 receptor, thereby suppressing the JAK signal transducer and activator of transcription signaling pathway, thus lowering the release of inflammatory molecules [92]. Many clinical trials to examine the efficacy of this agent are currently ongoing, but promising results of tocilizumab treatment in severe COVID-19 cases have recently been reported, with suggested remission of lung lesions in $95 \%$ of patients [93]. Likewise, since IL-1 was increased in some patients with COVID-19 [3], blockade of the proinflammatory IL-1 pathway might reduce hyperinflammation in 
COVID-19. Indeed, a retrospective cohort study of patients with COVID-19, acute respiratory distress syndrome, and hyperinflammation managed with noninvasive ventilation outside of the ICU showed that IL-1 blockade with high-dose anakinra in patients with COVID-19 was safe and associated with clinical improvement in $72 \%$ of patients [94]. Obviously, confirmation of efficacy will require controlled clinical trials that are currently ongoing [37, 75]. Other immunosuppressants that are currently being tested for their potential in patients with COVID-19 include leflunomide, which also inhibits virus replication, and thalidomide [37]. Furthermore, due to their rapid immunosuppressive effect, corticosteroids are frequently used in hyperinflammatory conditions (including COVID-19) to control immune-mediated damage of lung tissue. Although the efficacy of corticosteroids in patients with COVID-19 remains to be further investigated, promising first results of the large Randomised Evaluation of COVID-19 Therapy (RECOVERY) trial have very recently been published [95]. These preliminary data indicated that in patients hospitalized with COVID-19, dexamethasone treatment (6 mg once daily for up to 10 days versus usual care) reduced 28-day mortality among those receiving invasive mechanical ventilation or oxygen at randomization, but not among patients not receiving respiratory support [95]. Alternative immune-modulating strategies currently under clinical investigation for the treatment of COVID-19 include stem cell therapy and convalescent plasma treatment $[37,75]$, but the results of these trials are not yet available. It is likely that the many controlled clinical trials that are currently ongoing will reveal whether certain of these immune-modulating drugs may prove beneficial in patients with COVID-19.

\section{RAAS-Modulating Drugs}

The "SARS-CoV-2-RAAS axis" may provide an opportunity to leverage the different aspects of RAAS inhibitors to mitigate the viral-induced injuries and disease severity in patients with COVID-19. ACE inhibitors and Ang II type 1 receptor blockers (ARBs) mitigate the deleterious effects of unopposed Ang II action through the Ang II type 1 receptor [55], which in turn decreases blood pressure, inflammation, and lung injury, among other beneficial effects [66]. Given the link between obesity, increased RAAS activity, (adipose tissue) inflammation, and more detrimental outcomes of COVID-19 in people living with obesity, it is interesting to note that long-term ARB treatment also decreased the adipose tissue gene expression of macrophage infiltration markers in people with obesity [96]. Furthermore, it has previously been demonstrated in rodents that ACE inhibitors and ARBs may upregulate ACE2 expression [97], which might in theory increase viral entry into the cell. Therefore, it has been speculated that such modulation of RAAS activity might be harmful in people at risk or in patients with COVID-19 [98, 99]. Noteworthy, however, ACE2 levels are often high in diseased states, likely secondary to high RAAS activity [66]. In contrast, it has been hypothesized that ACE2 may be beneficial rather than detrimental in patients with lung injury, based on preclinical data and retrospective human studies demonstrating that RAAS inhibition decreases lung injury and improves survival, while simultaneously decreasing viral load in animal models with viral infections that utilize the ACE2 receptor [66, 70]. Importantly, however, the effects of RAAS modulators on tissue-specific ACE2 levels and activity in humans are currently not well understood. Several recent reports have consistently found that the use of RAAS inhibitors was not associated with the risk of SARS-CoV-2 infection, the risk of severe COVID-19 among those infected, or the risk of in-hospital death among those with a positive test [100-104]. Further controlled clinical trials are needed, and underway, to investigate the safety and efficacy of RAAS inhibition and treatment with recombinant human ACE2 to tackle the COVID-19 pandemic, as well as to provide a better mechanistic understanding of the effects of RAAS modulation on tissue-specific ACE2 levels [75]. Importantly, the putative cardiometabolic consequences of pharmacological agents directly targeting ACE2 should be carefully investigated.

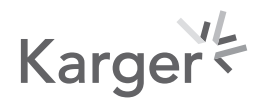




\section{Generating More Reliable Data under Time Constraints}

It is likely that multiple disease peaks will occur before herd (population) immunity is established. A major scientific challenge will be to align the results of small clinical studies during the current "first COVID-19 peak" and, based on these outcomes, initiate a set of wellcontrolled large clinical trials in later disease peaks to provide the scientific evidence needed for approval of pharmacological agents to combat the COVID-19 pandemic.

Inadequate preclinical studies impose a high risk of failure in clinical trials and may increase the risk of ambiguous findings. Traditional systematic reviews and meta-analyses only retrospectively include published studies to provide an evidence base for interventions [105]. With respect to COVID-19, most of the registered COVID-19 trials have small patient sizes, and it will take quite some time before data are published [75]. In order to maximize the value of small clinical studies with suboptimal study designs and to minimize bias of ongoing and future COVID-19 trials, prospective meta-analysis approaches may be considered [106]. Prospective meta-analyses predefine eligible studies for inclusion before the results of these clinical trials have been published in order to objectively address planned high-priority research questions for which previous evidence is scarce, but where new studies are rapidly emerging [107]. Since this approach may serve as an innovative solution to generate reliable data for guiding clinical management and regulatory decision-making [107], results from several clinical trials that are investigating the same intervention for patients with COVID-19 with compatible study designs and outcome measures could be combined. Importantly, this approach would require methodological expertise as well as the willingness and feasibility to work together and share data [106].

Although large, randomized, controlled trials of SARS-CoV-2 vaccines are currently the most efficient, generalizable, and scientifically robust path to establishing vaccine efficacy, controlled human infection models (CHIMs) have also been proposed as a strategy for accelerating SARS-CoV-2 vaccine development [108]. CHIMs require infecting healthy persons with a well-characterized microorganism in order to study pathogenesis, characterize the immune response, and elucidate the efficacy of vaccines or therapeutics. SARS-CoV-2 CHIMs could minimize the uncertainty about exposure or disease acquisition inherent in field trials, thereby reducing the number of participants needed to establish the desired end point, and elucidate the duration of immunity conferred by vaccines undergoing field trials [108]. Importantly, ethical considerations related to SARS-CoV-2 CHIMs have been raised as to whether the societal benefits are sufficient to justify the risks posed by deliberately exposing humans to SARS-CoV-2 [109-111].

Furthermore, it is crucial to obtain a better understanding of putative interindividual differences in treatment responses. This may, among others, be related to differences in health status, pharmacokinetics (i.e., reduced drug clearance in individuals with impaired liver or kidney function) [37], and vaccine effectiveness [112]. Therefore, careful characterization of patients (i.e., detailed phenotyping) is crucial to optimize treatment responses for different subgroups of patients, taking age, sex, body fat mass and distribution, and (distinct) obesityrelated complications into account, among other factors. Since obesity is a major risk factor for the development and progression of COVID-19, consideration of the adiposity-based chronic disease conceptual framework of obesity [113] may be of particular importance in this case.

\section{Concluding Remarks}

Improved strategies to deal with the dual challenges posed by the obesity and COVID-19 pandemics are urgently needed. To accomplish this, a better understanding of disease pathophysiology and progression as well as vaccination and treatment opportunities are required.

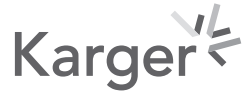


The current COVID-19 pandemic highlights the importance of understanding shared disease pathophysiology, which may steer therapeutic choices to prevent or dampen the complications of COVID-19, especially in vulnerable populations with higher risks of worse clinical outcomes such as people living with obesity and related NCDs. Detailed phenotyping of patients with COVID-19 is essential to identify individuals or subgroups at increased risk of developing this disease and to better predict disease progression and outcomes. In particular, the putative role of (abdominal) adipose tissue in the development and progression of COVID-19 warrants further investigation.

The many ongoing clinical trials in patients with COVID-19 will likely reveal the potential effects of different therapies. At the same time, the rapidly emerging clinical data require ongoing scrutiny to understand not only the risks and benefits of single drugs to tackle COVID-19, but also the interaction with pharmacological agents commonly used in people with obesity and related NCDs, including type 2 diabetes and cardiovascular diseases, who are especially at risk of or hospitalized with SARS-CoV-2 infection.

The issues discussed in this perspective have important implications for people living with obesity, health systems, and society at large. The COVID-19 pandemic will pass, but it is likely that multiple peaks will follow in the near future. In the past few months there have been a tremendous number of misleading claims about COVID-19, mostly on social media, intended to cause confusion about vaccination as a way to protect against infection. Researchers can and should contribute to tackling deliberately misleading and/or false information, for example by collaborating with organizations responding to such disinformation and by engaging the public in scientific discussions [114]. Researchers must report research findings accurately and in an unbiased manner and should be transparent about all scientific aspects throughout the hopefully successful journey to safe and effective COVID-19 vaccines and treatments.

The EASO will continue collaboration and discussion with its members and relevant stakeholders to discuss important issues related to preventive measures, access to care, vaccination, and future therapeutic strategies to combat the COVID-19 pandemic, and will continue to advocate for the importance of research and surveillance during and after the COVID-19 pandemic. The EASO therefore calls on the European Commission and all member states to work together to ensure that prevention and intervention strategies to manage obesity and related NCDs are more readily available. Obesity should be prioritized because of its major impact on the development of NCDs, especially during the present COVID-19 pandemic, but also thereafter to dampen the number of future COVID-19 cases. Since many new reports on COVID-19 rapidly appear, the present perspective should be seen as a focus for discussion to drive forward our understanding, research initiatives, as well as clinical management of COVID-19.

\section{Conflict of Interest Statement}

All authors declare no conflict of interest in the development of this perspective, which was authored under the auspices of the EASO. G.H. Goossens, D. Dicker, N.J. Farpour-Lambert, G. Frühbeck, D. Mullerova, E. Woodward, and J.-C. Holm are members of the Executive Committee of the EASO and receive no funding for that role.

\section{Funding Sources}

None.

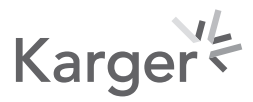




\begin{tabular}{l|l}
\hline Obes Facts 2020;13:439-452 \\
\hline DOI: 10.1159/000510719 & $\begin{array}{l}\text { ○ 2020 The Author(s). Published by S. Karger AG, Basel } \\
\text { www.karger.com/ofa }\end{array}$ \\
\hline
\end{tabular}

Goossens et al.: Obesity and COVID-19: Immunological Challenges and Opportunities

\section{References}

1 WHO. WHO Director-General's opening remarks at the media briefing on COVID-19-11 March 2020. www. who.int/dg/speeches/detail/who-director-general-s-opening-remarks-at-the-media-briefing-on-covid-1911-march-2020.

2 Verity R, Okell LC, Dorigatti I, Winskill P, Whittaker C, Imai N, et al. Estimates of the severity of coronavirus disease 2019: a model-based analysis. Lancet Infect Dis. 2020 Jun;20(6):669-77.

3 Huang C, Wang Y, Li X, Ren L, Zhao J, Hu Y, et al. Clinical features of patients infected with 2019 novel coronavirus in Wuhan, China. Lancet. 2020 Feb;395(10223):497-506.

4 Guan WJ, Ni ZY, Hu Y, Liang WH, Ou CQ, He JX, et al.; China Medical Treatment Expert Group for Covid-19. Clinical characteristics of coronavirus disease 2019 in China. N Engl J Med. 2020 Apr;382(18):1708-20.

5 Chen N, Zhou M, Dong X, Qu J, Gong F, Han Y, et al. Epidemiological and clinical characteristics of 99 cases of 2019 novel coronavirus pneumonia in Wuhan, China: a descriptive study. Lancet. 2020 Feb;395(10223):50713.

6 Onder G, Rezza G, Brusaferro S. Case-fatality rate and characteristics of patients dying in relation to COVID-19 in Italy. JAMA. 2020 doi: 10.1001/jama.2020.4683 [Epub ahead of print].

7 Richardson S, Hirsch JS, Narasimhan M, Crawford JM, McGinn T, Davidson KW, et al.; and the Northwell COVID-19 Research Consortium. Presenting Characteristics, Comorbidities, and Outcomes Among 5700 Patients Hospitalized With COVID-19 in the New York City Area. JAMA. 2020 Apr;323(20):2052.

8 Clarification of mortality rate and data in abstract, results, and table 2. JAMA. 2020 Apr;323(20):2098.

9 Remuzzi A, Remuzzi G. COVID-19 and Italy: what next? Lancet. 2020 Apr;395(10231):1225-8.

10 Grasselli G, Zangrillo A, Zanella A, Antonelli M, Cabrini L, Castelli A, et al.; COVID-19 Lombardy ICU Network. Baseline Characteristics and Outcomes of 1591 Patients Infected With SARS-CoV-2 Admitted to ICUs of the Lombardy Region, Italy. JAMA. 2020 Apr;323(16):1574.

11 Docherty AB, Harrison EM, Green CA, Hardwick HE, Pius R, Norman L, et al.; ISARIC4C investigators. Features of 20133 UK patients in hospital with covid-19 using the ISARIC WHO Clinical Characterisation Protocol: prospective observational cohort study. BMJ. 2020 May;369:m1985.

12 Frühbeck G, Baker JL, Busetto L, Dicker D, Goossens GH, Halford JC, et al. European Association for the Study of Obesity Position Statement on the Global COVID-19 Pandemic. Obes Facts. 2020;13(2):292-6.

13 Kopelman PG. Obesity as a medical problem. Nature. 2000 Apr;404(6778):635-43.

14 Frühbeck G, Toplak H, Woodward E, Yumuk V, Maislos M, Oppert JM; Executive Committee of the European Association for the Study of Obesity. Obesity: the gateway to ill health - an EASO position statement on a rising public health, clinical and scientific challenge in Europe. Obes Facts. 2013;6(2):117-20.

15 Van Kerkhove MD, Vandemaele KA, Shinde V, Jaramillo-Gutierrez G, Koukounari A, Donnelly CA, et al.; WHO Working Group for Risk Factors for Severe H1N1pdm Infection. Risk factors for severe outcomes following 2009 influenza A (H1N1) infection: a global pooled analysis. PLoS Med. 2011 Jul;8(7):e1001053.

16 Sun Y, Wang Q, Yang G, Lin C, Zhang Y, Yang P. Weight and prognosis for influenza A(H1N1)pdm09 infection during the pandemic period between 2009 and 2011: a systematic review of observational studies with metaanalysis. Infect Dis (Lond). 2016 Nov-Dec;48(11-12):813-22.

17 Wang B, Li R, Lu Z, Huang Y. Does comorbidity increase the risk of patients with COVID-19: evidence from meta-analysis. Aging (Albany NY). 2020 Apr;12(7):6049-57.

18 Cariou B, Hadjadj S, Wargny M, Pichelin M, Al-Salameh A, Allix I, et al.; CORONADO investigators. Phenotypic characteristics and prognosis of inpatients with COVID-19 and diabetes: the CORONADO study. Diabetologia. 2020 Aug;63(8):1500-15.

19 Simonnet A, Chetboun M, Poissy J, Raverdy V, Noulette J, Duhamel A, et al.; LICORN and the Lille COVID-19 and Obesity study group. High prevalence of obesity in severe acute respiratory syndrome coronavirus-2 (SARSCoV-2) requiring invasive mechanical ventilation. Obesity (Silver Spring). 2020 Jul;28(7):1195-9.

20 Lighter J, Phillips M, Hochman S, Sterling S, Johnson D, Francois F, et al. Obesity in patients younger than 60 years is a risk factor for Covid-19 hospital admission. Clin Infect Dis. 2020 Jul;71(15):896-7.

21 Intensive Care National Audit \& Research Centre. Audit I. ICNARC Report on COVID-19 in Critical Care April 10 2020. London, UK: Intensive Care National Audit \& Research Centre; 2020. www.icnarc.org/about/latestnews/2020/04/04/report-on-2249-patients-critically-ill-with-covid-19.

22 Goyal P, Choi JJ, Pinheiro LC, Schenck EJ, Chen R, Jabri A, et al. Clinical Characteristics of Covid-19 in New York City. N Engl J Med. 2020 Jun;382(24):2372-4.

23 Busetto L, Bettini S, Fabris R, Serra R, Dal Pra' C, Maffei P, et al. Obesity and COVID-19: an Italian snapshot. Obesity (Silver Spring). 2020 doi: 10.1002/oby.22918 [Epub ahead of print].

24 Caussy C, Pattou F, Wallet F, Simon C, Chalopin S, Telliam C, et al.; COVID Outcomes HCL Consortium and Lille COVID-Obesity Study Group. Prevalence of obesity among adult inpatients with COVID-19 in France. Lancet Diabetes Endocrinol. 2020 Jul;8(7):562-4.

25 Honce R, Schultz-Cherry S. Impact of Obesity on Influenza A Virus Pathogenesis, Immune Response, and Evolution. Front Immunol. 2019 May;10:1071.

26 Dhurandhar NV, Bailey D, Thomas D. Interaction of obesity and infections. Obes Rev. 2015 Dec;16(12):101729.

27 Kanneganti TD, Dixit VD. Immunological complications of obesity. Nat Immunol. 2012 Jul;13(8):707-12.

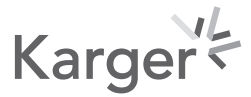


Goossens et al.: Obesity and COVID-19: Immunological Challenges and Opportunities

28 Ng M, Fleming T, Robinson M, Thomson B, Graetz N, Margono C, et al. Global, regional, and national prevalence of overweight and obesity in children and adults during 1980-2013: a systematic analysis for the Global Burden of Disease Study 2013. Lancet. 2014 Aug;384(9945):766-81.

29 Goossens GH. The Metabolic Phenotype in Obesity: Fat Mass, Body Fat Distribution, and Adipose Tissue Function. Obes Facts. 2017;10(3):207-15.

30 Rosen ED, Spiegelman BM. What we talk about when we talk about fat. Cell. 2014 Jan;156(1-2):20-44.

31 Wernstedt Asterholm I, Tao C, Morley TS, Wang QA, Delgado-Lopez F, Wang ZV, et al. Adipocyte inflammation is essential for healthy adipose tissue expansion and remodeling. Cell Metab. 2014 Jul;20(1):103-18.

32 Mohamed-Ali V, Goodrick S, Rawesh A, Katz DR, Miles JM, Yudkin JS, et al. Subcutaneous adipose tissue releases interleukin-6, but not tumor necrosis factor-alpha, in vivo. J Clin Endocrinol Metab. 1997 Dec;82(12):4196200.

33 Fontana L, Eagon JC, Trujillo ME, Scherer PE, Klein S. Visceral fat adipokine secretion is associated with systemic inflammation in obese humans. Diabetes. 2007 Apr;56(4):1010-3.

34 Bekkering S, Saner C, Riksen NP, Netea MG, Sabin MA, Saffery R, et al. Trained Immunity: Linking Obesity and Cardiovascular Disease across the Life-Course? Trends Endocrinol Metab. 2020 May;31(5):378-89.

35 Green WD, Beck MA. Obesity altered T cell metabolism and the response to infection. Curr Opin Immunol. 2017 Jun; 46:1-7.

36 Khan S, Chan YT, Revelo XS, Winer DA. The Immune Landscape of Visceral Adipose Tissue During Obesity and Aging. Front Endocrinol (Lausanne). 2020 May;11:267.

37 Zhong J, Tang J, Ye C, Dong L. The immunology of COVID-19: is immune modulation an option for treatment? Lancet Rheumatol. 2020;2(7):E428-36.

38 McLaughlin T, Ackerman SE, Shen L, Engleman E. Role of innate and adaptive immunity in obesity-associated metabolic disease. J Clin Invest. 2017 Jan;127(1):5-13.

39 Karlsson EA, Beck MA. The burden of obesity on infectious disease. Exp Biol Med (Maywood). 2010 Dec; 235(12):1412-24.

40 Sheridan PA, Paich HA, Handy J, Karlsson EA, Hudgens MG, Sammon AB, et al. Obesity is associated with impaired immune response to influenza vaccination in humans. Int J Obes. 2012 Aug;36(8):1072-7.

41 Paich HA, Sheridan PA, Handy J, Karlsson EA, Schultz-Cherry S, Hudgens MG, et al. Overweight and obese adult humans have a defective cellular immune response to pandemic H1N1 influenza A virus. Obesity (Silver Spring). 2013 Nov;21(11):2377-86.

42 Perlman S, Dandekar AA. Immunopathogenesis of coronavirus infections: implications for SARS. Nat Rev Immunol. 2005 Dec;5(12):917-27.

43 Xu Z, Shi L, Wang Y, Zhang J, Huang L, Zhang C, et al. Pathological findings of COVID-19 associated with acute respiratory distress syndrome. Lancet Respir Med. 2020 Apr;8(4):420-2.

44 Mahallawi WH, Khabour OF, Zhang Q, Makhdoum HM, Suliman BA. MERS-CoV infection in humans is associated with a pro-inflammatory Th1 and Th17 cytokine profile. Cytokine. 2018 Apr;104:8-13.

45 Wong CK, Lam CW, Wu AK, Ip WK, Lee NL, Chan IH, et al. Plasma inflammatory cytokines and chemokines in severe acute respiratory syndrome. Clin Exp Immunol. 2004 Apr;136(1):95-103.

46 Fang Y, Zhang H, Xu Y, Xie J, Pang P, Ji W. CT Manifestations of Two Cases of 2019 Novel Coronavirus (2019nCoV) Pneumonia. Radiology. 2020 Apr;295(1):208-9.

47 Chen G, Wu D, Guo W, Cao Y, Huang D, Wang H, et al. Clinical and immunological features of severe and moderate coronavirus disease 2019. J Clin Invest. 2020 May;130(5):2620-9.

48 Wan S, Yi Q, Fan S, Lv J, Zhang X, Guo L, et al. Characteristics of lymphocyte subsets and cytokines in peripheral blood of 123 hospitalized patients with 2019 novel coronavirus pneumonia (NCP). medRxiv. 2020 doi: 10.1101/2020.02.10.20021832.

49 Zhou Y, Fu B, Zheng X, Wang D, Zhao C, Qi Y, et al. Aberrant pathogenic GM-CSF+ T cells and inflammatory CD14+CD16+ monocytes in severe pulmonary syndrome patients of a new coronavirus. bioRxiv. 2020 doi: $10.1101 / 2020.02 .12 .945576$.

50 Wang D, Hu B, Hu C, Zhu F, Liu X, Zhang J, et al. Clinical Characteristics of 138 Hospitalized Patients With 2019 Novel Coronavirus-Infected Pneumonia in Wuhan, China. JAMA. 2020 Feb;323(11):1061-9.

51 Mehta P, McAuley DF, Brown M, Sanchez E, Tattersall RS, Manson JJ; HLH Across Speciality Collaboration, UK. COVID-19: consider cytokine storm syndromes and immunosuppression. Lancet. 2020 Mar;395(10229): 1033-4.

52 Tan L, Kang X, Ji X, Li G, Wang Q, Li Y, et al. Validation of predictors of disease severity and outcomes in COVID-19 patients: a descriptive and retrospective study. Med (NY). 2020 doi 10.1016/j.medj.2020.05.002 [Epub ahead of print].

53 Kuo CL, Pilling LC, Atkins JL, Masoli JA, Delgado J, Kuchel GA, et al. APOE e4 genotype predicts severe COVID-19 in the UK Biobank community cohort. J Gerontol A Biol Sci Med Sci. 2020 May:glaa131.

54 Tudorache IF, Trusca VG, Gafencu AV. Apolipoprotein E - a multifunctional protein with implications in various pathologies as a result of its structural features. Comput Struct Biotechnol J. 2017 Jun;15:359-65.

55 Goossens GH, Blaak EE, van Baak MA. Possible involvement of the adipose tissue renin-angiotensin system in the pathophysiology of obesity and obesity-related disorders. Obes Rev. 2003 Feb;4(1):43-55.

56 Timmermans PB, Wong PC, Chiu AT, Herblin WF, Benfield P, Carini DJ, et al. Angiotensin II receptors and angiotensin II receptor antagonists. Pharmacol Rev. 1993 Jun;45(2):205-51. 


\begin{tabular}{l|l}
\hline Obes Facts 2020;13:439-452 \\
\hline DOI: 10.1159/000510719 & $\begin{array}{l}\text { ○ 2020 The Author(s). Published by S. Karger AG, Basel } \\
\text { www.karger.com/ofa }\end{array}$ \\
\hline
\end{tabular}

Goossens et al.: Obesity and COVID-19: Immunological Challenges and Opportunities

57 Engeli S, Negrel R, Sharma AM. Physiology and pathophysiology of the adipose tissue renin-angiotensin system. Hypertension. 2000 Jun;35(6):1270-7.

58 Goossens GH. The renin-angiotensin system in the pathophysiology of type 2 diabetes. Obes Facts. 2012;5(4): 611-24.

59 Ferrario CM, Strawn WB. Role of the renin-angiotensin-aldosterone system and proinflammatory mediators in cardiovascular disease. Am J Cardiol. 2006 Jul;98(1):121-8.

60 Gheblawi M, Wang K, Viveiros A, Nguyen Q, Zhong JC, Turner AJ, et al. Angiotensin-Converting Enzyme 2: SARS-CoV-2 Receptor and Regulator of the Renin-Angiotensin System: Celebrating the 20th Anniversary of the Discovery of ACE2. Circ Res. 2020 May;126(10):1456-74.

61 Carey RM, Siragy HM. Newly recognized components of the renin-angiotensin system: potential roles in cardiovascular and renal regulation. Endocr Rev. 2003 Jun;24(3):261-71.

62 Li W, Moore MJ, Vasilieva N, Sui J, Wong SK, Berne MA, et al. Angiotensin-converting enzyme 2 is a functional receptor for the SARS coronavirus. Nature. 2003 Nov;426(6965):450-4.

63 Hoffmann M, Kleine-Weber H, Schroeder S, Kruger N, Herrler T, Erichsen S, et al. SARS-CoV-2 cell entry depends on ACE2 and TMPRSS2 and is blocked by a clinically proven protease inhibitor. Cell. 2020 Apr; 181(2):271-80.e8.

64 Zhou P, Yang XL, Wang XG, Hu B, Zhang L, Zhang W, et al. A pneumonia outbreak associated with a new coronavirus of probable bat origin. Nature. 2020 Mar;579(7798):270-3.

65 Xu X, Chen P, Wang J, Feng J, Zhou H, Li X, et al. Evolution of the novel coronavirus from the ongoing Wuhan outbreak and modeling of its spike protein for risk of human transmission. Sci China Life Sci. 2020 Mar;63(3): 457-60.

66 Ingraham NE, Barakat AG, Reilkoff R, Bezdicek T, Schacker T, Chipman JG, et al. Understanding the reninangiotensin-aldosterone-SARS-CoV axis: a comprehensive review. Eur Respir J. 2020 Jul;56(1):2000912.

67 Wrapp D, Wang N, Corbett KS, Goldsmith JA, Hsieh CL, Abiona O, et al. Cryo-EM structure of the 2019-nCoV spike in the prefusion conformation. Science. 2020 Mar;367(6483):1260-3.

68 Li W, Zhang C, Sui J, Kuhn JH, Moore MJ, Luo S, et al. Receptor and viral determinants of SARS-coronavirus adaptation to human ACE2. EMBO J. 2005 Apr;24(8):1634-43.

69 Wang C, Xie J, Zhao L, Fei X, Zhang H, Tan Y, et al. Alveolar macrophage activation and cytokine storm in the pathogenesis of severe COVID-19. Nat Res. 2020 doi: 10.21203/rs.3.rs-19346/v1 [Epub ahead of print].

70 Vaduganathan M, Vardeny O, Michel T, McMurray JJ, Pfeffer MA, Solomon SD. Renin-Angiotensin-Aldosterone System Inhibitors in Patients with Covid-19. N Engl J Med. 2020 Apr;382(17):1653-9.

71 Liu Y, Yang Y, Zhang C, Huang F, Wang F, Yuan J, et al. Clinical and biochemical indexes from 2019-nCoV infected patients linked to viral loads and lung injury. Sci China Life Sci. 2020 Mar;63(3):364-74.

72 Wang M, Cao R, Zhang L, Yang X, Liu J, Xu M, et al. Remdesivir and chloroquine effectively inhibit the recently emerged novel coronavirus (2019-nCoV) in vitro. Cell Res. 2020 Mar;30(3):269-71.

73 Wang C, Li W, Drabek D, Okba NM, van Haperen R, Osterhaus AD, et al. A human monoclonal antibody blocking SARS-CoV-2 infection. Nat Commun. 2020 May;11(1):2251.

74 Jiang RD, Liu MQ, Chen Y, Shan C, Zhou YW, Shen XR, et al. Pathogenesis of SARS-CoV-2 in transgenic mice expressing human angiotensin-converting enzyme 2. Cell. 2020 Jul;182(1):50-58.e8.

75 Lythgoe MP, Middleton P. Ongoing Clinical Trials for the Management of the COVID-19 Pandemic. Trends Pharmacol Sci. 2020 Jun;41(6):363-82.

76 Pillaiyar T, Meenakshisundaram S, Manickam M. Recent discovery and development of inhibitors targeting coronaviruses. Drug Discov Today. 2020 Apr;25(4):668-88.

77 Guy RK, DiPaola RS, Romanelli F, Dutch RE. Rapid repurposing of drugs for COVID-19. Science. 2020 May; 368(6493):829-30.

78 Plantone D, Koudriavtseva T. Current and Future Use of Chloroquine and Hydroxychloroquine in Infectious, Immune, Neoplastic, and Neurological Diseases: A Mini-Review. Clin Drug Investig. 2018 Aug;38(8):653-71.

79 Vincent MJ, Bergeron E, Benjannet S, Erickson BR, Rollin PE, Ksiazek TG, et al. Chloroquine is a potent inhibitor of SARS coronavirus infection and spread. Virol J. 2005 Aug;2(1):69.

80 Ruiz-Irastorza G, Olivares N, Ruiz-Arruza I, Martinez-Berriotxoa A, Egurbide MV, Aguirre C. Predictors of major infections in systemic lupus erythematosus. Arthritis Res Ther. 2009;11(4):R109.

81 Sisó A, Ramos-Casals M, Bové A, Brito-Zerón P, Soria N, Muñoz S, et al. Previous antimalarial therapy in patients diagnosed with lupus nephritis: influence on outcomes and survival. Lupus. 2008 Apr;17(4):281-8.

82 Gautret P, Lagier JC, Parola P, Hoang VT, Meddeb L, Mailhe M, et al. Hydroxychloroquine and azithromycin as a treatment of COVID-19: results of an open-label non-randomized clinical trial. Int J Antimicrob Agents. 2020 Jul;56(1):105949.

83 International Society of Antimicrobial Chemotherapy. Statement on IJAA paper. www.isac.world/news-andpublications/official-isac-statement [accessed April 21, 2020].

84 Chen Z, Hu J, Zhang Z, Jiang S, Han S, Yan D, et al. Efficacy of hydroxychloroquine in patients with COVID-19: results of a randomized clinical trial. medRxiv. 2020 doi: 10.1101/2020.03.22.20040758.

85 Geleris J, Sun Y, Platt J, Zucker J, Baldwin M, Hripcsak G, et al. Observational Study of Hydroxychloroquine in Hospitalized Patients with Covid-19. N Engl J Med. 2020 Jun;382(25):2411-8.

86 Mahévas M, Tran VT, Roumier M, Chabrol A, Paule R, Guillaud C, et al. Clinical efficacy of hydroxychloroquine in patients with covid-19 pneumonia who require oxygen: observational comparative study using routine care data. BMJ. 2020 May;369:m1844. 
87 Tang W, Cao Z, Han M, Wang Z, Chen J, Sun W, et al. Hydroxychloroquine in patients with mainly mild to moderate coronavirus disease 2019: open label, randomised controlled trial. BMJ. 2020 May;369:m1849.

88 Magagnoli J, Narendran S, Pereira F, Cummings T, Hardin JW, Sutton SS, et al. Outcomes of hydroxychloroquine usage in United States veterans hospitalized with Covid-19. medRxiv. 2020 doi:10.1101/2020.04.16.20065920 [preprint].

89 Fihn SD, Perencevich E, Bradley SM. Caution Needed on the Use of Chloroquine and Hydroxychloroquine for Coronavirus Disease 2019. JAMA Netw Open. 2020 Apr;3(4):e209035.

90 Richardson P, Griffin I, Tucker C, Smith D, Oechsle O, Phelan A, et al. Baricitinib as potential treatment for 2019 nCoV acute respiratory disease. Lancet. 2020 Feb;395(10223):e30-1.

91 Hutchinson M, Tattersall RS, Manson JJ. Haemophagocytic lymphohisticytosis - an underrecognized hyperinflammatory syndrome. Rheumatology (Oxford). 2019 Nov;58(Suppl 6):vi23-30.

92 Riegler LL, Jones GP, Lee DW. Current approaches in the grading and management of cytokine release syndrome after chimeric antigen receptor T-cell therapy. Ther Clin Risk Manag. 2019 Feb;15:323-35.

93 Xu X, Han M, Li T, Sun W, Wang D, Fu B, et al. Effective treatment of severe COVID-19 patients with tocilizumab. Proc Natl Acad Sci USA. 2020 May;117(20):10970-5.

94 Cavalli G, De Luca G, Campochiaro C, Della-Torre E, Ripa M, Canetti D, et al. Interleukin-1 blockade with highdose anakinra in patients with COVID-19, acute respiratory distress syndrome, and hyperinflammation: a retrospective cohort study. Lancet Rheumatol. 2020 Jun;2(6):e325-31.

95 Horby P, Lim WS, Emberson J, Mafham M, Bell J, Linsell L, et al. Effect of dexamethasone in hospitalized patients with COVID-19: preliminary report. medRxiv. 2020 doi: 10.1101/2020.06.22.20137273.

96 Goossens GH, Moors CC, van der Zijl NJ, Venteclef N, Alili R, Jocken JW, et al. Valsartan improves adipose tissue function in humans with impaired glucose metabolism: a randomized placebo-controlled double-blind trial. PLoS One. 2012;7(6):e39930.

97 Ferrario CM, Jessup J, Chappell MC, Averill DB, Brosnihan KB, Tallant EA, et al. Effect of angiotensin-converting enzyme inhibition and angiotensin II receptor blockers on cardiac angiotensin-converting enzyme 2. Circulation. 2005 May;111(20):2605-10.

98 Fang L, Karakiulakis G, Roth M. Are patients with hypertension and diabetes mellitus at increased risk for COVID-19 infection? Lancet Respir Med. 2020 Apr;8(4):e21.

99 Esler M, Esler D. Can angiotensin receptor-blocking drugs perhaps be harmful in the COVID-19 pandemic? J Hypertens. 2020 May;38(5):781-2.

100 Yang G, Tan Z, Zhou L, Yang M, Peng L, Liu J, et al. Effects of angiotensin II receptor blockers and ACE (angiotensin-converting enzyme) inhibitors on virus infection, inflammatory status, and clinical outcomes in patients with COVID-19 and hypertension: a single-center retrospective study. Hypertension. 2020 Jul;76(1):51-8.

101 Mehra MR, Desai SS, Kuy S, Henry TD, Patel AN. Cardiovascular disease, drug therapy, and mortality in Covid-19. N Engl J Med. 2020 Jun;382(25):e102 [retracted].

102 Mancia G, Rea F, Ludergnani M, Apolone G, Corrao G. Renin-Angiotensin-Aldosterone System Blockers and the Risk of Covid-19. N Engl J Med. 2020 Jun;382(25):2431-40.

103 Reynolds HR, Adhikari S, Pulgarin C, Troxel AB, Iturrate E, Johnson SB, et al. Renin-Angiotensin-Aldosterone System Inhibitors and Risk of Covid-19. N Engl J Med. 2020 Jun;382(25):2441-8.

104 Li J, Wang X, Chen J, Zhang H, Deng A. Association of Renin-Angiotensin System Inhibitors With Severity or Risk of Death in Patients With Hypertension Hospitalized for Coronavirus Disease 2019 (COVID-19) Infection in Wuhan, China. JAMA Cardiol. 2020 Apr;5(7):825.

105 Paul M, Leibovici L. Systematic review or meta-analysis? Their place in the evidence hierarchy. Clin Microbiol Infect. $2014 \mathrm{Feb}$;20(2):97-100.

106 Ma Z, Liu J, Pan Q. Overwhelming COVID-19 Clinical Trials: Call for Prospective Meta-Analyses. Trends Pharmacol Sci. 2020 Aug;41(8):501-3.

107 Seidler AL, Hunter KE, Cheyne S, Ghersi D, Berlin JA, Askie L. A guide to prospective meta-analysis. BMJ. 2019 Oct;367:15342.

108 Deming ME, Michael NL, Robb M, Cohen MS, Neuzil KM. Accelerating development of SARS-CoV-2 vaccines the role for controlled human infection models. N Engl J Med. 2020 doi: 10.1056/NEJMp2020076 [Epub ahead of print].

109 Eyal N, Lipsitch M, Smith PG. Human Challenge Studies to Accelerate Coronavirus Vaccine Licensure. J Infect Dis. 2020 May;221(11):1752-6.

110 Shah SK, Miller FG, Darton TC, Duenas D, Emerson C, Lynch HF, et al. Ethics of controlled human infection to address COVID-19. Science. 2020 May;368(6493):832-4.

111 Plotkin SA, Caplan A. Extraordinary diseases require extraordinary solutions. Vaccine. 2020 May;38(24): 3987-8.

112 Neidich SD, Green WD, Rebeles J, Karlsson EA, Schultz-Cherry S, Noah TL, et al. Increased risk of influenza among vaccinated adults who are obese. Int J Obes. 2017 Sep;41(9):1324-30.

113 Frühbeck G, Busetto L, Dicker D, Yumuk V, Goossens GH, Hebebrand J, et al. The ABCD of Obesity: An EASO Position Statement on a Diagnostic Term with Clinical and Scientific Implications. Obes Facts. 2019;12(2): 131-6.

114 Ball P, Maxmen A. The epic battle against coronavirus misinformation and conspiracy theories. Nature. 2020 May;581(7809):371-4. 